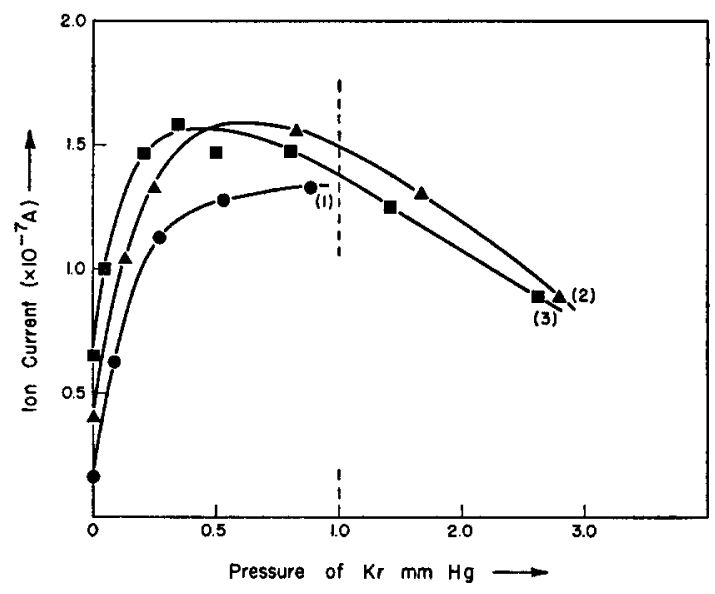

FIG. 2. Ion current of NO gas with krypton. Voltage between two electrodes: $22.5 \mathrm{v}$. (1) Pressure of NO gas $=0.088 \mathrm{~mm} \mathrm{Hg}$. (2) Pressure of NO gas $=0.26 \mathrm{~mm} \mathrm{Hg}$. (3) Pressure of $\mathrm{NO}$ gas $=0.49 \mathrm{~mm} \mathrm{Hg}$.

The authors wish to thank Dr. F. P. Lossing for discussions and advice during the course of this work.

* National Research Council Contribution No. NRC 4243 .
† Japanese Government Fellow at the National Research Council of Canada 1954-1955 and National Research Council Post-doctorate Fellow $1955-1957$.

1 Wainfan, Walker, and Weissler, J. Appl. Phys. 24, 1318 (1953). K Watanabe. J. Chem. Phys. 22, 1564 (1954) gives a good bibliography.

2 F. P. Lossing and Ikuzo Tanaka, J. Chem. Phys. 25, 1031 (1956).

$3 \mathrm{~W}$. E. Groth, Z. physik. Chem. N. F. 1, 300 (1954).

- It is assumed that the reactions $\mathrm{Kr} r^{*}+\mathrm{Kr}=\mathrm{Kr}^{\prime}+\mathrm{Kr}^{\prime}, \mathrm{NO}^{*}+\mathrm{Kr}=\mathrm{NO}^{\prime}$ $+\mathrm{Kr} \mathbf{r}^{\prime}$ are small and may be neglected.

\section{Structure of $\mathrm{CH}_{2}$}

\section{G. A. GALLUP}

Department of Chemistry, University of Nebraska, Lincoln, Nebraska (Received November 26, 1956)

$\mathbf{R}$

ECENT mechanism studies have created interest in the question of the spin multiplicity in the molecular fragment, $\mathrm{CH}_{2}$. The case for the singlet state has been argued, giving as evidence observations on the reaction of diazomethane with olefins. ${ }^{1}$ Quantum-mechanical discussions of the electronic state of $\mathrm{CH}_{2}$ have been either qualitative or used some assumed constant $\mathrm{H}-\mathrm{C}-\mathrm{H}$ angle in the treatment.2

On the experimental side, Herzberg ${ }^{3}$ has shown from its spectrum that $140^{\circ}$ is a reasonable $\mathrm{H}-\mathrm{C}-\mathrm{H}$ angle for $\mathrm{CH}_{2}$ assuming the $\mathrm{C}-\mathrm{H}$ distance is the same as in $\mathrm{CH}_{4}$. By analogy with $\mathrm{CF}_{2}$ Duchesne and Burnelle ${ }^{4}$ have assumed the ground state of $\mathrm{CH}_{2}$ to be singlet.

The present note concerns a detailed quantum-mechanical calculation, using the LCAO-MO approximation, undertaken to determine if numerical calculations indicate any preference of one state over the other.

The AO's used were C: $2 s, 2 p_{x}, 2 p_{y}, 2 p_{z}$ and a $1 s$ on each hydrogen. One of the $\mathrm{C} 2 p$ 's may be oriented perpendicular to the plane of $\mathrm{CH}_{2}$, if the $\mathrm{H}-\mathrm{C}-\mathrm{H}$ angle is not $180^{\circ}$. This $2 p$, therefore, does not overlap any of the other AO's, and a $5 \times 5$ secular determinant must be solved. Symmetry orbitals simplify the actual calculation, of course. All overlap integrals were included in the calculation, including the one between the two hydrogens. The energies of the five nonlocalized MO's were determined for values from $90^{\circ}$ to $180^{\circ}$ of the $\mathrm{H}-\mathrm{C}-\mathrm{H}$ angle. The diagonal elements of the determinant were assumed to be empirically determined $\mathrm{AO}$ energies for carbon and hydrogen, and the off diagonal elements were approximated as:

$$
H_{i j}=\frac{1}{2}\left(H_{i i}+H_{i j}-10.0\right) S_{i j}
$$

where $S_{i j}$ is the overlap between the $i$ th and $j$ th $\mathrm{AO}$, and the -10.0 term was used in a crude attempt to include the interaction between an electron associated with one nucleus and an adjacent nucleus. The carbon-hydrogen overlaps were obtained from tables ${ }^{5}$ assuming a $\mathrm{C}-\mathrm{H}$ distance of $1.09 \mathrm{~A}$. The hydrogenhydrogen overlap changes with the $\mathrm{H}-\mathrm{C}-\mathrm{H}$ angle.

The calculated energies of the three of the MO's are lower than that of the noninteracting $2 p$ (except at $180^{\circ}$ ). We may consider two electrons in each of these three orbitals and obtain the singlet state. If two electrons are placed in each of the two lowest MO's, one in the third MO, and one in the noninteracting $2 p$, the triplet state is obtained. Figure 1 shows the variation of the energy of

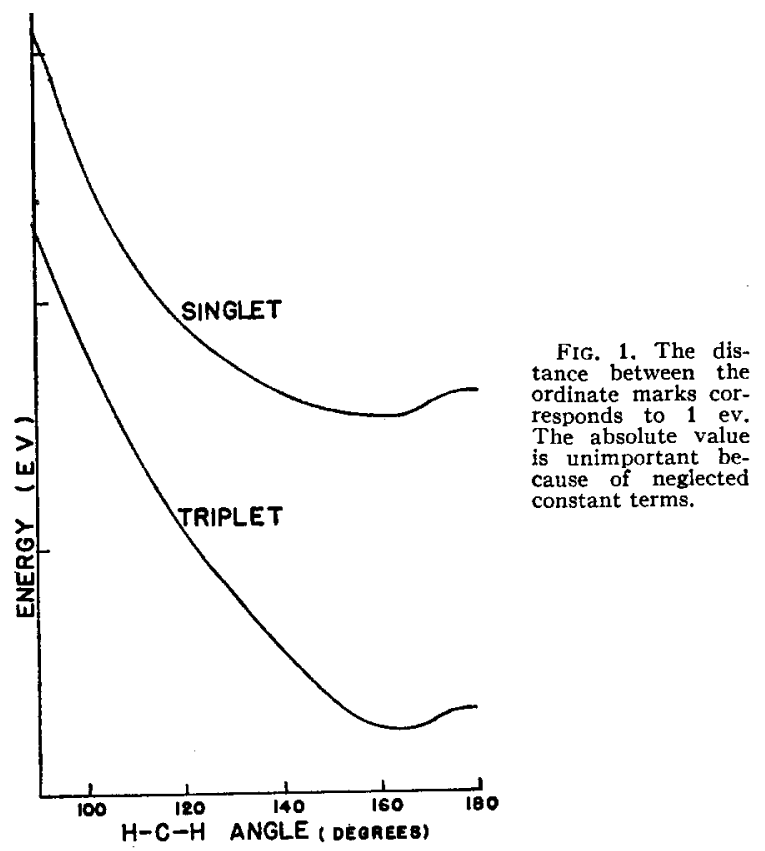

the singlet and triplet states with $\mathrm{H}-\mathrm{C}-\mathrm{H}$ angle. Both curves include repulsion between the two protons, and the singlet curve includes $+1.3 \mathrm{ev}$ which is the energy difference between the ${ }^{1} D$ and ${ }^{3} P$ states for carbon, it being assumed that the energy required to pair electrons in the same orbital in $\mathrm{CH}_{2}$ is roughly the same as in carbon. Both curves show a minimum around $160^{\circ}$, but the triplet state has the lower energy. On the basis of this calculation with its assumptions it appears that $\mathrm{CH}_{2}$ exists in a triplet ground state; the calculated angle of $160^{\circ}$ is not too far from $140^{\circ}$.

1 P. S. Skell and R, C. Woodworth, J. Am. Chem. Soc. 78, 4496 (1956). 2 (a) J. Lennard-Jones, Trans. Faraday Soc. 30,70 (1934); (b) J. Lennard2 (a) J. Lennard-Jones, Trans. Faraday Soc. 30, $70(1934) ;$ (b) J. Lennard-
Jones and J. A. Pople, Discussions Faraday Soc. 10, 9 (1951); (c) H. H. Jones and J. A. Pople, Discussions Faraday Soc. 10, 9 (1951); (c) H. H.
Voge, J. Chem. Phys. 4, 581 (1936); (d) K. J. Laidler and E. J. Casey,
ibid. 17, 213 (1949); (e) A. D. Walsh, Discussions Faraday Soc. 2, 18 (1947). \&G. Herzberg, Revs. Modern Phys. 14, 195 (1942); Astrophys. J. 96, 314 (1942)

1942) Duchesne and L. Burnelle, J. Chem. Phys. 21, 2005 (1953).

5 Mulliken, Rieke, Orloff, and Orloff, J. Chem. Phys. 17, 1248 (1949).

\section{Vibrational Spectrum of $\mathbf{N}$-Methyl Formamide}

$$
\begin{aligned}
& \text { D. E. DeGraAf AND G. B. B. M. SUTHERLAND* } \\
& \text { The Harrison M. Randall Laboratory of Physics, } \\
& \text { University of Michigan, Ann Arbor, Michigan }
\end{aligned}
$$
(Received October 17, 1956)

DREVIOUS studies of the vibrational spectrum of $\mathrm{N}$-methyl formamide (NMF) have been reported by several workers. ${ }^{1-4}$ We have recently completed more extensive investigations of the infrared and Raman spectra of NMF and NDNMF_ (N-deutero 
$\mathrm{N}$-methyl formamide). The new data obtained have made it possible to assign observed bands to all the 21 normal vibrations of NMF.

We have observed infrared spectra of NMF in the liquid and vapor states, and also in solution, in the range $\sim 320-3600 \mathrm{~cm}^{-1}$ Infrared spectra of NDNMF (liquid and solution) have been obtained in the region $\sim 320-3600 \mathrm{~cm}^{-1}$. In addition, polarized Raman spectra of liquid NMF and NDNMF were obtained in the range $225-3600 \mathrm{~cm}^{-1}$.

A trans-model having a plane of symmetry was adopted as the most probable configuration of NMF. The observed bands have been assigned on the basis both of their association and deuteration shifts, and the depolarization ratios of the Raman lines, where these could be measured. These assignments for liquid NMF and NDNMF are summarized in Table $\mathbf{I}$.

TABLE 1. Fundamental vibrations in liguid $\mathrm{N}$-methyl formamide and $\mathrm{N}$-deutero N-methyl formamide.

\begin{tabular}{|c|c|c|}
\hline \multirow[b]{2}{*}{ Vibration } & \multicolumn{2}{|c|}{ Observed band $\left(\mathrm{cm}^{-1}\right)$} \\
\hline & $\begin{array}{c}\text { N-methyl } \\
\text { formamide }\end{array}$ & $\begin{array}{l}\text { N-deutero } \\
\text { N-methyl } \\
\text { formamide }\end{array}$ \\
\hline $\begin{array}{l}\text { NH stretching } \\
\mathrm{C}^{\prime} \mathrm{H} \text { asym. stretchings } \\
\text { (doubly degenerate) }\end{array}$ & $\begin{array}{l}3301 \\
2943\end{array}$ & 2943 \\
\hline $\begin{array}{l}\text { CH stretching } \\
\mathrm{CH}^{\prime} \mathrm{H} \text {; sym. stretching } \\
\text { ND stretching }\end{array}$ & $\begin{array}{l}2877 \\
2748\end{array}$ & $\begin{array}{l}2879 \\
2743 \\
2474\end{array}$ \\
\hline $\begin{array}{l}\text { Amide I } \\
\text { Amide II }\end{array}$ & $\begin{array}{l}1667 \\
1543\end{array}$ & $\begin{array}{l}1665 \\
1436\end{array}$ \\
\hline $\begin{array}{l}\mathrm{C}^{\prime} \mathrm{H}_{s} \text { asym. deformation } \\
\text { (doubly degenerate) }\end{array}$ & 1450 & 1467 \\
\hline $\mathrm{C}^{*} \mathrm{H}$ s sym. deformation & 1415 & 1405 \\
\hline $\mathrm{CH}$ wagginge & 1386 & 1383 \\
\hline Amide III & 1243 & 977 \\
\hline $\mathrm{C}^{\prime} \mathrm{H}$; wagging & 1148 & 1156 \\
\hline $\mathrm{C}^{\prime} \mathrm{H}_{s}$ rocking & 1012 & 1023 \\
\hline $\mathrm{C} N$ stretching & 956 & 940 \\
\hline $\mathrm{CH}$ rocking & 778 & 760 \\
\hline $\mathrm{NH}$ rocking & 714 & \\
\hline $\begin{array}{l}\text { CO wagging } \\
\text { ND rocking }\end{array}$ & 618 & $\begin{array}{l}610 \\
537\end{array}$ \\
\hline CN torsion & 356 & 351 \\
\hline CNC deformation & 302 & 295 \\
\hline $\mathrm{C}^{\prime} \mathrm{H}$ a torsion & 242 & not observed \\
\hline
\end{tabular}

- $C^{\prime}$ denotes the methyl carbon atom.

C denotes the carbonyl carbon atom.

d "Wagking" denotes in-plane motion.

The assignment of the $2877 \mathrm{~cm}^{-1}$ band to the $\mathrm{CH}$ stretching vibration is based in part on its large shift upon dissociation (to $2840 \mathrm{~cm}^{-1}$ in the vapor state), which is analogous to the behavior of the $\mathrm{CH}$ stretching band in formamide. ${ }^{5}$ The band at $778 \mathrm{~cm}^{-1}$ is depolarized in the Raman spectrum and hence must arise from an out-of-plane vibration. It is assigned to the CHrocking mode. This band corresponds to the $765 \mathrm{~cm}^{-1}$ band observed $^{5}$ for formamide, which we also ascribe to a $\mathrm{CH}$ rocking vibration.

The band at $618 \mathrm{~cm}^{-1}$ shifts markedly on dissociation, appearing at $576 \mathrm{~cm}^{-1}$ in the vapor state. This behavior, and the fact that this line is polarized in the Raman spectrum, strongly support the assignment of this band to an in-plane vibration involving considerable motion of the carbonyl oxygen atom. This vibration is here referred to as $\mathrm{CO}$ wagging, but may equally well be described as a deformation of the NCO angle. The Raman band at $302 \mathrm{~cm}^{-1}$ is polarized, and is assigned to the other in-plane skeletal deformation mode.

The $356 \mathrm{~cm}^{-1}$ band shifts to a lower frequency upon dilution, and is depolarized in the Raman spectrum. These facts support the assignment of this band to the torsional vibration of the two ends of the molecule about the $\mathrm{CN}$ bond. This torsional oscillation is largely a CO rocking motion.

A combination band of considerable interest occurs in NMF at $1314 \mathrm{~cm}^{-1}$, and shifts to $1119 \mathrm{~cm}^{-1}$ upon deuteration. These bands are attributed to the combination NH (ND) rocking plus $\mathrm{CO}$ wagging.
This work was supported, in part, by a grant from the U.S. Public Health Service, which is gratefully acknowledged. One of us (D.E.D.) expresses his thanks for a University Fellowship awarded by the University of Michigan.

* Present address: The National Physical Laboratory, Teddington, Middlesex, England.

tRandall, Fowler, Fuson, and Dangl, Infrared Determination of Organic Structures (D. Yan Nostrand Company, Inc. New York, 1949).

\%. B. Kessler, Ph, D, thesis, University of Michigan, 1952. IR. M. Badger and H. Rubalcava, Proc. Natl. Acad. Sci. U. S. 40, 12 $1954)$.

4 Miyazawa, Shimanouchi, and Mizushima, J. Chem. Phys. 24, 408

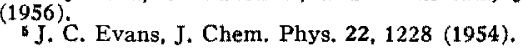

\section{Burning-Rate Studies. A Negative Pressure Exponent in the Consumption-Rate Equation for a Liquid System}

A. Greenville Whittaker, Harry Williams, and Penniman M, Rust Chemistry Disision, U.S. Noval Ordnance Test Station,

China Lake, California

(Received October 1, 1956)

PREVIOUSLY, two-component systems were studied as mixtures in stoichiometric proportions to give $\mathrm{CO}_{2}, \mathrm{H}_{2} \mathrm{O}$, and $\mathrm{N}_{2}$ as products of complete combustion. In order to get more information on the kinetics of the combustion of two-component systems a study of nonstiochiometric mixtures was initiated. Normally the consumption rate increases with pressure according to the relation

$$
C=k P^{n}+b,
$$

where $C$ is the consumption rate, $P$ is the pressure during combustion, and $k, n$, and $b$ are positive constants. During this study it was found that under certain conditions it is possible for $n$ to be negative over a limited pressure region.

Only the 2-nitropropane-95\% nitric acid system was used. The purity of materials, the apparatus and procedure used were the same as described elsewhere. ${ }^{1}$ The mixture ratio $R$ was defined by the function

$$
R=\frac{1}{1+F}
$$

where $F$ is the ratio of the fuel used to the fuel required for stoichiometric ratio to a given amount of oxidizer.

The results obtained are shown in Table I. Each rate value is the result of nine independent determinations. The average deviation was approximately $\pm 3 \%$. In the smooth-burning region, ${ }^{1}$ both oxidizer-rich and fuel-rich mixtures have higher consumption rates than the stoichiometric mixtures. Since the surface corrections for these systems were about the same, the same relation should hold for the fundamental burning rate. For mixtures which are far from stoichiometric proportions, the consumption rate becomes less than that of the stoichiometric mixture. Hence, it appears that in the smooth-burning region a plot of $R$ vs consumption rate at constant pressure would show two maxima, one on either side of the stoichiometric mixture. Euston $^{2}$ and Davidson ${ }^{3}$ made a similar study on the systems nitroethane-nitric acid and acetic acid-nitric acid, respectively. With their systems a plot of $R$ vs consumption rate showed a

TABLE 1. Effect of mixture ratio on the consumption rate of the system 2-nitropropane-95\% nitric acid at various pressures.

\begin{tabular}{ccccc}
\hline $\begin{array}{c}\text { Mixture } \\
\text { ratio } \\
R\end{array}$ & 28.2 atmos & 55.4 atmos & 82.6 atmos & 109.8 atmos \\
\hline $5 / 9$ & 0.653 & 0.777 & $1.68^{\mathrm{s}}$ & $3.40 \mathrm{a}$ \\
$1 / 2$ & 0.259 & 0.650 & $4.32^{\mathrm{s}}$ & $8.89 \mathrm{a}$ \\
$3 / 7$ & 0.368 & 0.625 & $2.47^{\mathrm{s}}$ & $6.65 \mathrm{~s}$ \\
$1 / 3$ & 0.102 & 0.351 & 0.508 & 0.508 \\
\hline
\end{tabular}

- Turbulent combustion. 